\section{Justice, Caring, and Animal Liberation}

\author{
Brian Luke \\ Virginia Polytechnic Institute
}

Editors' Note: The following paper by

Professor Luke and commentary by

Professor Menta were presented at the

Eastern Division meetings of the Society for

the Study of Ethics and Animals, held in

New York City, New York, December, 1991.

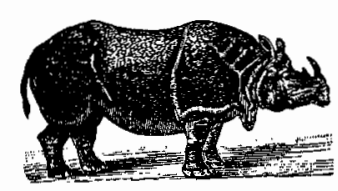

Carol Gilligan has described justice and caring as two distinct moral frameworks or orientations to ethical concerns. (Gilligan 1982) The justice framework is characterized by abstraction, the application of general rules of conduct, an emphasis on restraining aggression, and a concern for consistency and the fair resolution of conflicting claims and interests. The caring framework, on the other hand, is characterized by its focus on the concrete and particular, its emphasis on the maintenance and extension of connection, and by its concern for responsiveness and the satisfaction of needs. Animal liberation is often framed as a justice issue, though, I will suggest, it may more appropriately be understood in terms of caring.

By "animal liberation" I mean opposition to institutions of animal exploitation such as vivisection, hunting, and animal farming. Two prominent philosophical defenders of animal liberation are Tom Regan and Peter Singer. Both work exclusively within the justice framework, presenting animal liberation as a matter of consistency and fair treatment, rather than in terms of responsiveness and the satisfaction of needs. We can start to see how the justice approach is ill-suited for animal liberation by considering the arguments of Regan and Singer.

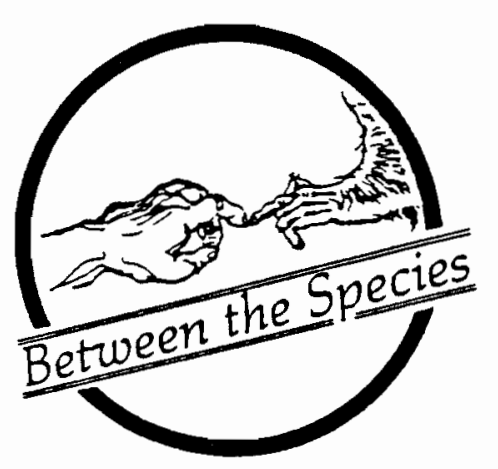

Regan attempts to move the reader from a commitment to the respectful treatment of humans to a like commitment to the respectful treatment of normal adult mammals. (Regan 1983) Regan points out that we do not in general think it justifiable to harm one human to benefit others-we would object, for example, to killing a healthy man against his will in order to use his organs to save three sick people. We do, however, think it appropriate to harm one animal to benefit other animals, human or otherwise; at least this is the way that vivisection, hunting, and animal farming are usually justified.

Regan argues that we are being inconsistent in treating humans and other mammals differently in this respect. The notion of inconsistency here is not selfcontradiction but contradiction with the formal principle of justice, according to which like individuals should be treated alike. Now we protect humans against being vivisected, farmed, or hunted, presumably because such treatment would harm them through the infliction of pain and death. But Regan has shown in the first three chapters of his book that pain and death are also harms to normal adult mammals. So these animals are just as deserving of protection from vivisection, farming, and hunting as are humans. Because both humans and other mammals are harmed by pain and death, the two groups are relevantly similar, and we are inconsistent to treat them so differently.

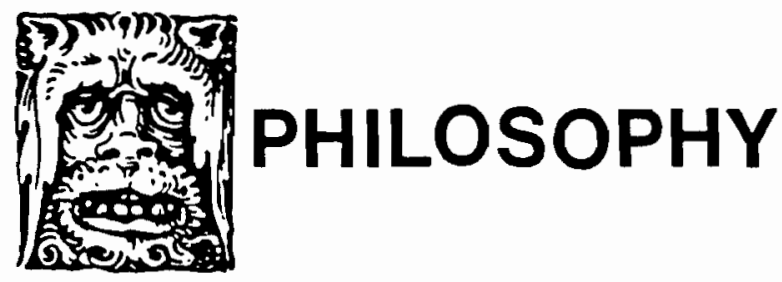


The flaw in this argument I wish to emphasize is the move from same kinds of harms to relevant similarity. Most of us would admit that pain and death are harms for both humans and other animals. But this by itself does not show that humans and other animals are relevantly similar with respect to assessing the moral status of these common harms. Regan allows that certain capacities may be unique to humans, and it is conceivable that the presence of uniquely human capacities in an individual is relevant to the justifiability of harming that individual, even when the type of harm in question is one which can be imposed on nonhumans. In fact, according to Kantian theories, only rational individuals can be directly wronged. A Kantian could hold that killing is a harm both to humans and other animals, but that the wrongness of the harm arises only from its impingement upon the victim's rationality. Thus, killing a rational human would require special justification not needed for killing a nonrational animal, even though both are harmed by being killed.

I am not saying that I agree with Kantianism or with the idea that there are uniquely human capacities. I am only saying that as long as Regan's readers are willing to embrace these theories, they can without inconsistency reject Regan's move from "death and pain are harms for both humans and other animals" to "killing and inflicting pain require the same justification for both humans and other animals." Since this move is crucial to his argument as a whole, they can consistently reject Regan's case for animal rights. ${ }^{1}$

Essentially the same type of maneuver allows rejection of Singer's argument for animal liberation. Like Regan, Singer attempts to move the reader, through considerations of consistency, from commitments concerning the appropriate treatment of humans to similar commitments concerning the appropriate treatment of animals. (Singer 1975, chapter 1) Singer starts not with respect for humans but with opposition to racism and sexism. Singer argues that anyone who opposes racism and sexism does so on the basis of a principle of equal consideration, according to which we must give equal consideration to the interests of all people, regardless of their race or sex. But animals, at least all those capable of feeling pleasure or pain, have interests, so there is no reason, according to Singer, why they should be excluded from the scope of this principle of equal consideration. But animal farming and vivisection, Singer maintains, are considered acceptable practices only because we tend to give the interests of nonhumans much less consideration than the similar interests of humans. This devaluation of interests solely on the basis of species Singer calls "speciesism," and he thinks his argument shows that we are inconsistent to oppose sexism and racism but not speciesism.

As with Regan, however, anyone willing to accept a Kantian view can reject Singer's entire argument without inconsistency. Singer presumes that opposition to sexism and racism must be based on the principle of equal consideration of interests. One could maintain, however, that sexism and racism are objectionable because they are disrespectful of the rationality of members of the oppressed races and sex. One could then consistently exclude nonhumans from moral consideration, by holding that they lack the rational capacities of humans.

Again I emphasize that I am not endorsing Kantianism here. I am just showing that Regan's and Singer's arguments fail on their own terms. Both writers insist that they are relying on reason alone, and not emotion, to establish their animal liberationist conclusions. But the crucial step in their arguments, that humans and other animals are relevantly similar, cannot be established by reason alone.

Regan and Singer have the following response for Kantian rebuttals of their arguments. (see Singer 1975, Regan 1979, Singer 1990) Taking rationality as a necessary condition for moral considerability does give one permission to harm animals (if rationality is defined narrowly enough). But it also gives permission to harm many nonrational humans, such as infants, mentally retarded individuals, and people with brain damage or in comas. Thus, a commitment to protect these so-called "marginal cases" of humanity entails the rejection of Kantianism and the adoption of some more inclusive criterion of considerability. But any criterion broad enough to include marginal humans (e.g., sentience or subjectivity) will also include nonhuman animals and thus support animal liberation.

This line of thought, called "the argument from marginal cases," is no more successful than Regan's and Singer's main arguments in proving that animals have rights. On the one hand, the argument may be circumvented simply by giving up the commitment to protect marginal humans. R. G. Frey does this. He takes the marginal cases argument to present a dilemma: either oppose animal vivisection or condone the vivisection of marginal humans. (Frey 1983:97) He then reasons: 
[V]ery few people indeed would look in the face the benefits which medical research in particular has conferred upon us, benefits which on the whole have most certainly involved vivisections.... [T] herefore, we may find ourselves unable to make the choice in favour of antivivisectionism.... Accordingly, we are left with human experiments. I think this is how I would choose, not with great glee and rejoicing, and with great reluctance; but if this is the price we must pay to hold the appeal to benefit and to enjoy the benefits which that appeal licenses, then we must, I think, pay it. (Frey 1983:97)

Frey forgets that "we" academics, presumably (hopefully?) escaping classification as marginal, would not be the ones to pay the real price for a choice in favor of vivisection.

Even those of us not quite able to match Frey's noble sacrifice of other humans to vivisection can still consistently evade the marginal cases argument, if we are so inclined. Suppose we "justify" the vivisection of animals by reference to their supposed lack of rationality. And suppose we allow that some humans also lack this rationality. This does not imply that we must vivisect marginal humans, only that we may. Thus, the protection of marginal humans could be made consistent with the vivisection of animals possessing comparable degrees of rationality by interpreting that protection as supererogatory. According to this line of thought we may vivisect marginal humans, because, like nonhuman animals, they lack a right to protection, but for nonbinding reasons we decide only to vivisect the nonhuman animals. This stratagem is employed by Bonnie Steinbock:

I am willing to admit that my horror at the thought of experiments being performed on severely mentally incapacitated human beings in cases in which I would find it justifiable and preferable to perform the same experiments on non-human animals (capable of similar suffering) may not be a moral emotion. But it is certainly not wrong of us to extend special care to members of our own species. (Steinbock 1978:256)

So like their main arguments, Regan's and Singer's backup argument from marginal cases fails to show any unavoidable inconsistency in supporting the exploitation of animals in vivisection and in farming while rejecting any similar exploitation of humans. Animal liberation is not a matter of consistency.

As arguments, justice-based approaches to animal liberation fail. The justice orientation also fails to capture the moral outlooks of many in the animal liberation movement. Justice-oriented writers cast the issue as, fundamentally, a comparison between the treatment of humans and the treatment of other animals. According to Regan, we harm animals to benefit others, we do not do this to humans (generally speaking), but there is no relevant difference between humans and animals to justify the dissimilar treatment. Thus animals are treated unfairly by comparison to the treatment of humans. For Singer, the comparative unfairness is in opposing sexism and racism but not opposing speciesism, when again there is no relevant difference between humans and other animals to support the distinction. For both Regan and Singer, and other writers within the justice framework, the basic moral judgment concerns the discrepancy between the treatment of humans and the treatment of other similar animals. What is called into question is the fairness, or what they more often refer to as the consistency, of a society which treats two relevantly similar groups of individuals in such totally different ways.

The emphasis on the consistency of the agent and the focus on comparing the treatment of humans and the treatment of other animals are quite distant from my motivations and those of others in the animal liberation movement. My opposition to the institutionalized exploitation of animals is not based on a comparison between human and animal treatment but on a consideration of the abuse of the animals by itself. I respond directly to the needs and the plight of the animals used in vivisection, hunting and farming. In objecting to these practices I am not comparing the treatment of humans and animals and thinking "this is unfair because humans are protected from such usage." I am appalled by the abuses in and of themselvesshooting, trapping, and poisoning; branding, castrating, forcibly impregnating, separating mother and young, tail docking, debeaking, confining, transporting in cattle cars, and slaughtering; burning, cutting, gassing, starving, asphyxiating, decapitating, decompressing, irradiating, electrocuting, freezing, crushing, paralyzing, amputating, excising organs, removing parts of the 
brain, socially isolating, inducing addiction, and imposing disease-these acts are repellant because of what they do to the animals. My moral condemnation of the acts arises directly from my sympathy for the animals, and is independent of the question of whether humans are protected from such abuse. To the extent that humans are also treated in these ways I object to that, too, but again, out of sympathy and not considerations of fairness.

Let me give some examples of discourse which clearly show the sort of direct responsiveness I am talking about. A 1983 study on the psychology of slaughter contains quotes from college students who worked on a farm as part of their curriculum. One 19-year-old woman wrote:

The first time I went into the slaughter room I had just haltered and pulled a steer into the waiting line. I could tell that the steer sensed what was going to happen to him. He was doing anything to get away. Then when I walked to the slaughter.room I was amazed at the amount of blood. It was an awful feeling to look at that steer with its eyes open and his feet pointing up, so I had to look at the ceiling. Mr. _ told me to cut off the head with a saw. I couldn't do it so I left. I guess slaughtering affects me more than the usual person because I raised calves for $4-\mathrm{H}$ at home and became quite attached to them-but I don't butcher them. (Herzog \& McGee 1983:129-30)

\section{A 19-year-old man wrote:}

It's pretty gross. I don't like having the dry heaves all day. Plus, I feel really bad for the cow. It's bad seeing a big animal turned into hamburger. (Herzog \& McGee 1983:130)

The reactions described here are not comparative judgments of justice such as, "cutting off this steer's head is wrong because we don't do that to humans," but, rather, revulsion at bloodshed, pity for an animal struggling for his life, memories of animal friends, a sense of the loss and the waste of "a big animal turned into hamburger"-all elements of caring. Now these students do not identify themselves as animal liberationists, but the reactions they describe do not differ essentially from the reactions on which animal liberation is often based. Consider the following statements by people who do support animal liberation, either partially or completely:

[T] he production-line maintenance of animals, ... is without a doubt one of the darkest and most shameful chapters in human culture. If you have ever stood before a stable where animals are being fattened and have heard hundreds of calves bleating, if you can understand the calf's cry for help, then you will have had enough of those people who derive profit from it.

I eat meat but rarely veal ... I could never bring myself to slaughter a cow. This is very difficult to do to any animal that one has taken care of for a long time. (Lorenz 1988:113)

Ninety percent of all pigs are now raised in indoor, near-dark, windowless confinement sheds.... I respond on an emotional level with horror at what each individual pig is subjected to and sympathize with each pig, whose extreme sociability is evidenced by these animals' increased popularity as pets.... As a lactating mother, I empathize with the sow whose reproductive freedoms have been denied and whose nursing experience seems so wretched. As a consumer and a vegetarian, I visualize this information when I witness people buying or eating "ham," "bacon," or "sausage." (Adams 1991:134)

I was one morning, while studying alone in the Natural History Museum, suddenly disturbed by a frightful burst of screams, of a character more distressing than words can convey, proceeding from some chamber on another side of the building. I called the porter in charge of the museum, and asked him what it meant. He replied with a grin, "It is only the dogs being vivisected in Monsieur Beclard's laboratory." ... Therewith he left me, and I sat down alone and listened. Much as I had heard and said, and even written, before that day about vivisection, I found myself then for the first time in its actual presence, and there swept over me a wave of such extreme mental anguish that my heart stood still under it.... 
And then and there, burying my face in my hands, with tears of agony I prayed for strength and courage to labour effectually for the abolition of so vile a wrong, and to do at least what one heart and voice might to root this curse of torture from the land. (Anna Kingsford, quoted in Vyvyan 1988:122-23)

No comparisons of human and animal treatment, or fixation on one's own consistency; upon seeing or hearing how the animals are abused, there is an immediate reaction directed against that treatment, and based on that reaction, a moral judgment and decision to act.

In response to the criticism that their justice approach misses the fundamental importance of direct sympathetic responsiveness in the actual motivations of activists, Regan and Singer could point out that their work is not descriptive but normative, that is, that they are not trying to describe animal rights activists and their psyches (à la Susan Sperling (1988) or Keith Tester (1991)) but, rather, to set out the best reasons we have for accepting the animal rights position. Such a response would be inadequate in two ways. First, it is doubtful that justice-based arguments do present the best reasons for animal liberation, given that those arguments are unsound, as I have shown above. More importantly, this response would incompletely characterize the projects Singer and Regan take for themselves, since, besides attempting to construct sound arguments, both writers explicitly indicate that they also want to further the animal liberation movement. This second part of their project, I would suggest, makes it incumbent upon them to attend to the actual motivations of activists. Arguments with little relation to the ethics of those who already affirm animal liberation are unlikely to bring new people into the movement or to help present activists maintain their commitment. Those of us who write or speak to move others should make presentations consonant with the real processes by which individuals come to reject animal farming, vivisection, and hunting.

In fact, Regan and Singer believe that they are taking these processes sufficiently into account in constructing their justice-based arguments. Each believes that sympathetic responsiveness to animals is an insufficient basis for the development of an animal rights perspective in most individuals. They feel that justice-based argumentation, or what they call "reason," is necessary to augment people's sympathies.
I will now describe why they believe this and why I think they are mistaken.

Regan questions whether an ethic of care can "go far enough." (Regan 1991:95) He asks:

[W]hat are the resources within the ethic of care that can move people to consider the ethics of their dealings with individuals who stand outside the existing circle of their valued interpersonal relationships?... [U]nless we supplement the ethic of care with some other motivating force-some other grounding of our moral judgment-we run the grave risk that our ethic will be excessively conservative and will blind us to those obligations we have to people for whom we are indifferent.

Nowhere, perhaps, is this possibility more evident than in the case of our moral dealings with nonhuman animals. The plain fact is, most people do not care very much about what happens to them....

And thus it is that a feminist ethic that is limited to an ethic of care will, I think, be unable to illuminate the moral significance of the idea that we (human) animals are not superior to all other animals. (Regan 1991:95-6)

To remedy this supposed limitation of the caring approach Regan suggests the marshalling of "consistency" arguments such as those I have already discussed.

Singer does "not think that an appeal to sympathy and goodheartedness alone will convince most people of the wrongness of speciesism." (Singer 1975:255) He places his distrust of the caring approach within a sociobiological framework. In The Expanding Circle (Singer 1981), he argues that humans are disposed towards kin altruism, reciprocal altruism, and group altruism, and that these dispositions can be explained in evolutionary terms. Singer sees the capacity to reason and the practice of reason-giving as evolving independently of the evolution of our sympathetic dispositions. Reason, however, can act to override narrow sympathies, to expand our consideration beyond that yielded by kin, reciprocal, and group altruism. Singer argues that:

altruistic impulses once limited to one's kin and one's own group might be extended to a wider circle by reasoning creatures who 
can see that they and their kin are one group among others, and from an impartial point of view no more important than others. (Singer 1981:134)

So, for Singer, humans have evolved instinctive capacities to respond sympathetically only to a few individuals closely similar to or associated with themselves. Therefore reason, in the form of the principle of equal consideration of interests, must be applied for consideration to be extended to other clans, races, and species.

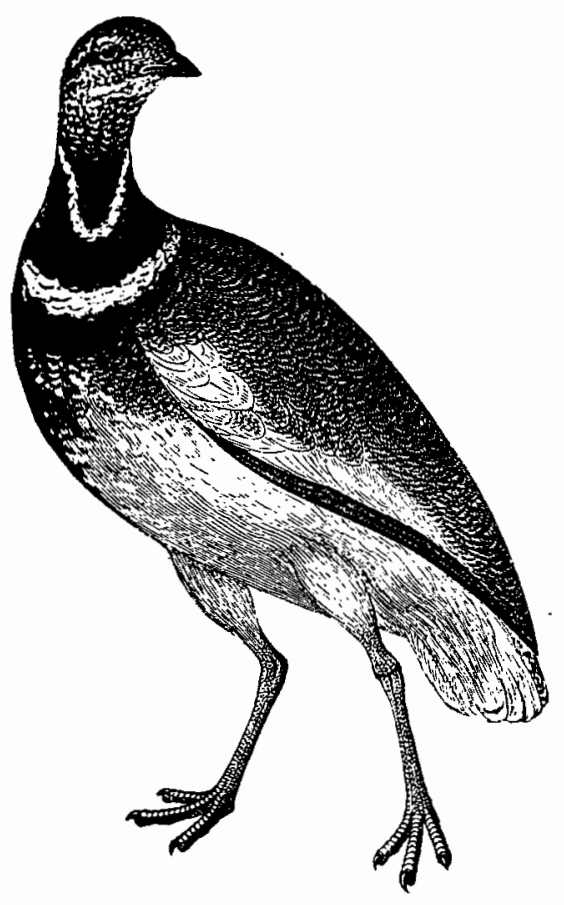

Given their low estimation of the human capacity to sympathize with nonhumans, we can understand why Regan and Singer might feel that their justice-oriented approaches to animal liberation are essential. If people do not care for animals, then supporters of animal liberation cannot presume that such affections are present in those they are trying to persuade. At best, they can assume the presence of some concern for humans and use this concern as a fulcrum, trying to impel their interlocutors to animal liberation through charges of inconsistency. This is precisely Regan's and Singer's justice-based strategy.

Now, I can understand how one might conclude that people do not care about animals, given the existence of such horrendous institutions as vivisection, factory farming, and sport hunting. Regan's and Singer's accounts, however, involve an overly simplistic understanding of the limitations of people's sympathies. For Regan it is a "plain fact" that people do not care about animals, while for Singer it is a genetic fact. On the contrary, I contend that this state of affairs is not "plain" but rather ornate, and it is not genetic but socially constructed. Animal exploitation thrives not because people fail to care but in spite of the fact that they do care.

The disposition to care for animals is not the unreliable quirk of a few, but is, rather, the normal state of humans generally. As Andree Collard puts it: "Our common bond with animals is natural (of nature), normal (of the norm), and healthy (wholesome)." (Collard 1989:70) If we shift our attention away from animal exploitation to other cultural phenomena, we can see the strength and depth of the human-animal bond. I will just mention four examples.

(1) Pet-keeping. The practice of keeping animals as companions, in its cross-cultural prevalence and its frequently avid pursuit, demonstrates the strength and depth of human interest in and affection for nonhuman animals. Approximately half of all contemporary Americans and Europeans have pets at any given time. Many theories of petkeeping downplay affectional ties, instead characterizing pets as, for example, status symbols or objects of domination. While this may accurately characterize some human-pet relationships, companionship and affection are by far the most important elements motivating pet-keeping in our society. In one survey, for example, pet-owners ranked companionship, love and affection, and pleasure, respectively, as the top three "advantages" of owning a pet. (Quigley, et al 1983:271) And as James Serpell has shown, the common practice of pet-keeping among tribal cultures, like pet-keeping in industrial Europe and America, is characterized by strong affection for pets, great efforts to keep pets, and views of pets as family and community members. (Serpell 1986, chapter 4) 
(2) Therapy. Many people either socially withdrawn or in depressed states have been helped through the companionship of animals. These people were unable to interact positively with other humans but could establish a connection with a friendly animal, often a dog or a cat. (see Beck \& Katcher 1983, chapter 8) This reinforces what most of us already recognize, that bonds with animals are sometimes easier to establish and maintain than bonds with humans.

(3) Rescue. You may recall from 1988 the plight of three California gray whales off the coast of Point Barrow, Alaska. The ice-holes through which the whales were surfacing to breathe were in the process of freezing over, which would result in the whales drowning. A rescue attempt was mounted, which ultimately cost $\$ 5.8$ million and directly involved all the following: local subsistence whalers, professional biologists, environmental activists, 150 journalists, the oil industry, U.S. National Guard, and the American and Soviet federal governments. (Rose 1989) If we ask why the rescue was pursued at such great lengths, a cynical answer in terms of the self-interest of the participants would be to some extent correct. But to leave it at that would give a very superficial and distorted understanding of the final cause of the rescue. The participation of these groups in the whales' rescue served their interests only by virtue of a deep and widespread concern for the whales' well-being among people generally. The media, for example, cannot play to emotions people do not have: whale rescues boost ratings because people care about whales, especially whales that have become individualized through their special circumstances.

(4) Expiation. James Serpell describes the almost universal presence, in cultures which hunt or slaughter animals, of mechanisms for mediating the guilt which such exploitation engenders. (Serpell 1986: chapters 10 and 11) Mechanisms which soothe the consciences of those who harm animals take many forms. Consider the following: many African tribes perform elaborate cleansing and purification ceremonies after killing an animal, others apologize to the slain (Serpell 1986:145); ancient Babylonian priests, as part of the rite of animal sacrifice, would whisper in the slaughtered victim's ear: "This deed was done by all the gods; I did not do it" (168); the Nuer people of the Sudan justify their consumption of cattle blood by claiming that periodic bleeding is beneficial to the animals' health (153), while the Ainu of Japan also claim to benefit the bears they eat, by maintaining that bears want to return to the spirit realm from which they came (148). Western civilization has its own expiatory myths, most outstandingly the biblical fable of divinely granted dominion over animals, and the scientific denial of animal subjectivity (originally expressed as Cartesian animal automatism, now more circumspectly maintained as operational behaviorism).

All these rituals and myths serve in some way to reduce the guilt-feelings of those who harm animals. The general occurrence of guilt-mediating mechanisms around systems of animal exploitation contradicts the notion that humans are naturally indifferent toward animal welfare. People are generally inclined against harming animals: otherwise, there would be no need for social mechanisms which make killing somewhat more bearable - the exploitation of animals would be as psychologically straightforward as, say, drinking water or breathing air.

Attention to social phenomena such as pet-keeping, animal rescues, therapeutic human-animal relationships, and the ubiquity of expiatory mechanisms around animal exploitation brings a realization of the depth of the human-animal connection. This realization shifts the question, from Regan's and Singer's "How can we get people to oppose animal exploitation, given that they don't care?" to "How does animal exploitation continue, given that people do care?" The answer I would give to this latter question is that animal exploitation continues with great difficulty. Enormous amounts of social energy are expended to forestall, undermine, and override our sympathies for animals, so that vivisection, animal farming, and sport hunting can continue.

Let me mention just a few of the myriad practices our society has developed to overcome opposition to harming animals.

There is a great deal of concealment and distortion of what is done to animals in laboratories and on farms. Vivisectors self-consciously conceal the effects of their activities from the public, through such measures as removing the vocal cords of vivisected dogs (so their 
tortured howling does not attract sympathy) and disposing of carcasses surreptitiously. Special terminology blunts awareness of what is done, such as "terminate," "dispatch," and "sacrifice" for killing. The meat industry also employs euphemisms, preferring, for example, "meat-packing" to "slaughtering." And the images of farm life presented in advertising and children's books consistently show contented animals living in harmony with human guardians, rather than the nightmarish reality of the factory farm and the slaughterhouse.

Beyond obscuring what is done to animals, there are also social mechanisms for negating the existence of the animals themselves. I have already mentioned the denial of animal subjectivity which has become intrinsic to scientific "objectivity." Our everyday language also removes the individual intentionality of exploited animals from awareness, through terms such as "livestock" (meaning "animals ... for sale and profit"-Webster's Unabridged Dictionary), and "game" ("animals ... pursued or killed in sport"). Animals referred to by such terms have come to be defined solely in terms of the purposes of their human exploiters. It is now of the essence of a "guinea pig" to be vivisected. This denial of the animal's own purposes is sometimes purposefully advocated:

Forget the pig is an animal. Treat him just like a machine in a factory. Schedule treatments like you would lubrication. Breeding season like the first step in an assembly line. And marketing like the delivery of finished goods. (Hog Farm Management, Sept. 1976. Quoted in Mason and Singer 1990:1)

Apart from devices which prevent sympathy, such as denying animal subjectivity or covering up how animals are harmed, there are also social mechanisms for overriding those sympathies which do become engaged. Perhaps the most potent of these is the myth of necessity - the idea that we must exploit animals for our own well-being. Both the meat industry and the vivisection industry actively promote the notion that they are serving essential human interests. Their largely false teachings - that human health depends upon programs of animal vivisection, and that meat, eggs, and dairy products are good for you-generate the kind of fear that prevents even those disturbed by the harms done to farmed and vivisected animals from taking a political stand against animal exploitation. ${ }^{2}$

Finally, numerous systems of reward and punishment insure that complicity with animal exploitation takes precedence over compassion. Children who are aghast at discovering the true origin of meat are forced by their parents to continue eating the dead flesh; aspiring vivisectors find that the lure of professional acclaim and financial comfort overcomes their initial inhibitions against killing and imposing disease; and slaughterhouse employees, hating every minute on the job, stomach it when no other jobs pay decent wages. (see Thompson 1983)

To sum up: Justice-based arguments for animal liberation fail. But my own experience and the reports of others lead me to believe that direct responsiveness to need is more central to animal liberationism than concerns about consistency anyway. And contrary to the suppositions of justice-oriented writers, the capacity to respond to animals is a deep and recurring feature of humans. That is precisely why societies which institutionalize animal exploitation must and do find ways to override our sympathetic capacities, or to prevent their actualization.

The lesson I draw from this analysis is twofold, part heartening and part sobering. Heartening is the realization that the ethical basis of animal liberation is very simple and generally moving. A straightforward presentation of what the animals are like and what is done to them on the farms and in the labs can stir people, especially if the ideologies which block sympathy are simultaneously debunked.

But sobering is a grasp of the nature of the social forces allied against a true perception of animals, against an understanding of what is done to them, against the possibility of acting from compassion. The substantial power of institutionalized animal exploitation sustains ignorance, promotes fear, rewards cruelty, and punishes kindness. So, though the ethics of animal liberation are inherently appealing, the obstacles placed in the way of radical social change based on sympathy are daunting. This is not to say that those obstacles are insurmountable. Moving away from unsound and irrelevant justice-based arguments, taking instead a caring perspective which expects a human-animal bond, and which challenges any hindrances to this natural, normal, and healthy bond, allows us to continue moving toward a society in which animals have been liberated from human tyranny. 


\section{Notes}

${ }^{1}$ I should note that Regan does not neglect this response to his argument: section 5.5 of his book is a rejection of Kantianism. Close examination, however, reveals that his argument against Kantianism is question-begging. See this author's doctoral dissertation.

${ }^{2}$ Convincing arguments that these are false appear in Sharpe (1988) and Robbins (1987).

\section{References}

Adams, Carol J. 1991. "Ecofeminism and the eating of animals." Hypatia 6: 125-145.

Beck, Alan, and Aaron Katcher. 1983. Between Pets and People: The Importance of Animal Companionship. New York: G.P. Putnam's Sons.

Collard, Andree, with Joyce Contrucci. 1989. Rape of the Wild: Man's Violence against Animals and the Earth. Bloomington: Indiana University Press.

Frey, R.G. 1983. "Vivisection, morals and medicine." Journal of Medical Ethics 9: 94-7.

Gilligan, Carol. 1982. In a Different Voice: Psychological Theory and Women's Development. Cambridge: Harvard University Press.

Herzog, Harold A. Jr., and Sandy McGee. 1983. "Psychological aspects of slaughter: reactions of college students to killing and butchering cattle and hogs." International Journal for the Study of Animal Problems 4: 124-132.

Katcher, Aaron, and Alan Beck, eds. 1983. New Perspectives on Our Lives with Companion Animals. Philadelphia: University of Pennsylvania Press.

Lorenz, Konrad. 1988. On Life and Living. New York: St. Martin's Press.

Mason, Jim, and Peter Singer. 1990. Animal Factories. New York: Harmony Books.

Quigley, Joseph, Lyle Vogel and Robert Anderson. 1983. "A study of perceptions and attitudes toward pet ownership." In Katcher and Beck: 266-275.

Regan, Tom. 1979. "An examination and defense of one argument concerning animal rights." Inquiry 22: 189-220.

Regan, Tom. 1983. The Case for Animal Rights. Berkeley: University of California Press.

Regan, Tom. 1991. The Thee Generation: Reflections on the Coming Revolution. Philadelphia: Temple University Press.
Robbins, John. 1987. Diet for a New America . Walpole, NH.: Stillpoint Publishing.

Rose, Tom. 1989. Freeing the Whales: How the Media Created the World's Greatest Non-Event. New York: Birch Lane Press.

Serpell, James. 1986. In the Company of Animals: A Study of Human-Animal Relationships. New York: Basil Blackwell.

Sharpe, Robert. 1988. The Cruel Deception: The Use of Animals in Medical Research. Wellingborough, England: Thorsons Publishing Group.

Singer, Peter. 1975. Animal Liberation. New York: Avon Books.

Singer, Peter. 1981. The Expanding Circle: Ethics and Sociobiology. New York: Farrar, Straus \& Giroux.

Singer, Peter. 1990. "The significance of animal suffering." Behavioral and Brain Sciences 13: 9-12.

Sperling, Susan. 1988. Animal Liberators: Research \& Morality. Berkeley: University of California Press.

Steinbock, Bonnie. 1978. "Speciesism and the idea of equality." Philosophy 53: 247-56

Tester, Keith. 1991. Animals \& Society: The Humanity of Animal Rights. London: Routledge.

Thompson, William. 1983. "Hanging tongues: a sociological encounter with the assembly line." Qualitative Sociology 6: 215-37.

Vyvyan, John. 1988. In Pity and in Anger. Marblehead, MA.: Micah Publications.

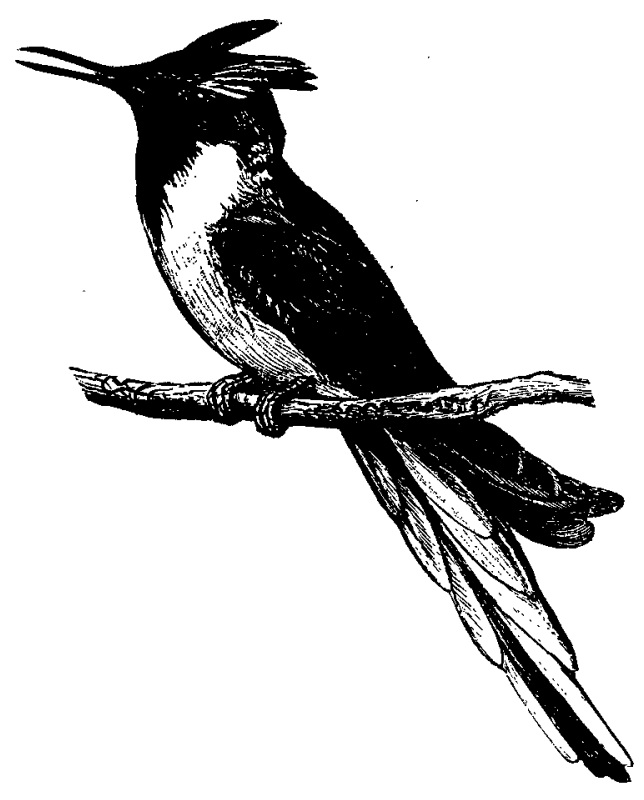

